\title{
Íkinci basamak bir acil serviste trombolitik tedavi deneyimi
}

\author{
Thrombolytic therapy experience in a secondary care emergency department
}

\author{
Mehmet Ali Aslaner, Necmi Baykan
}

Gönderilme tarihi:21.01.2019

Kabul tarihi:18.04.2019

Özet

Amaç: Trombolitik tedavi, ülkemizde üniversite ve eğitim-araştırma hastanelerinde sıklıkla uygulanmakta ve kullanım oranları daha net olarak tanımlanmış olmasına rağmen, ulusal literatürde ikinci basamak acil servis kullanım oranları bilinmemektedir. Bu çalışma ile ülkemizde eksik olan, ikinci basamağa ait yeni bir veri seti oluşturmak amaçlanmıştır.

Gereç ve Yöntem:Çalışma 2016-2018 yılları arasında geriye dönük olarak, Nevşehir ilinin en büyük hastanesinin ikinci basamak acil servisinde gerçekleştirildi. Veri seti; demografik özelliklerin yanı sıra, tanılar, kullanılan etken madde, komplikasyon durumu ve 3 aylık mortalite olarak belirlendi.

Bulgular: Çalışma periyodu boyunca 57 hastaya trombolitik tedavi verildi. Hastaların ortanca yaşı 68 (IQR 54-79) ve erkek cinsiyet oranı \%70,2 idi. Tüm çalışma boyunca trombolitik tedavi kullanım sıklığı 1,8/10.000 acil servis başvurusu olarak saptandı. Trombolitik tedavi uygulanan tanılar içerisinde; iskemik inme $\% 50,9$ oranında, akut miyokard enfarktüsü $\% 29,8$, arrest etiyolojisi $\% 10,5$ ve pulmoner tromboemboli $\% 8,8$ oranındaydı. Kullanılan ajanlardan alteplaz $\% 75,4$ oranında ve tenekteplaz $\% 24,6$ oranında uygulandı. Tedavi uygulanan tüm hastaların 3 aylık mortalite oranı \%57,9' idi.

Sonuç: Çalışmada, trombolitik tedavi uygulamasının daha sıklıkla iskemik inme hastalarında uygulandığı görüldü. Alteplaz, geniş endikasyon spektrumu nedeniyle en sık kullanılan trombolitik ajandı. Çalışma sonucunda trombolitik kullanımının, özellikle ikinci basamak acil servislerde oldukça düşük oranda olduğu düşünüldü.

Anahtar Kelimeler: Acil servis, trombolitik tedavi, alteplaz, tenekteplaz.

Aslaner MA, Baykan N. İkinci basamak bir acil serviste trombolitik tedavi deneyimi. Pam Tıp Derg 2019;12:309314.

\begin{abstract}
Purpose:Although thrombolytic therapy is frequently used and the usage rates are well defined in university and education-research hospitals in our country, secondary care emergency departments (ED) utilization rates in national literature are not known. With this study, it was aimed to create a new data set which is insufficient in our country.

Materials and Methods:The study was carried out retrospectively between 2016 and 2018 in the secondary care ED of the biggest hospital of Nevşehir province. Data set were included diagnoses, active substance, complication status and 3-months mortality in addition to demographic characteristics.

Results:During the study period, 57 patients received thrombolytic therapy. The median age of the patients was 68 (IQR 54-79) and the male gender ratio was $70.2 \%$. The frequency of thrombolytic therapy was $1.8 / 10.000$ in all ED visits. Of all diagnoses; the incidence of ischemic stroke was $50.9 \%$, acute myocardial infarction was $29.8 \%$, arrest etiology was $10.5 \%$ and pulmonary thromboembolism was $8.8 \%$. Alteplase was used in $75.4 \%$ of the cases and tenecteplase was used in $24.6 \%$. The mortality rate was $57.9 \%$ in all patients.

Conclusion:Thrombolytic therapy was more frequently performed in patients with ischemic stroke. Alteplase was the most commonly used thrombolytic agent because of its wide spectrum of indications. It was thought that thrombolytic usage is very low in the secondary care emergency departments.
\end{abstract}

Key Words: Emergency department, thrombolytic therapy, alteplase, tenekteplase.

Aslaner MA, Baykan N. Thrombolytic therapy experience in an secondary care emergency department. Pam Med J 2019;12:309-314.

Mehmet Ali Aslaner, Uzm. Dr. Nevşehir Devlet Hastanesi Acil Servisi, NEVŞEHIR, e-posta: maliaslaner@hotmail.com (orcid.org/0000-00027851-7881)

Necmi Baykan, Uzm. Dr. Nevşehir Devlet Hastanesi Acil Servisi, NEVŞEHIR, e-posta: drnecmibaykan@gmail.com (orcid.org/0000-0002-68459550) 


\section{Giriş}

Acil hekimleri çoğu zaman vasküler aciller ile ilk karşılaşan hekim grubudur. Bu hastalıklar içerisinde tartışmasız en önemlileri akut miyokardiyal enfarktüs (AMI), iskemik inme (SVO) ve pulmoner tromboembolidir (PTE). Fibrinolitik ajanları ve tedavilerini, hatta endikasyon ve kontrendikasyonlarını, bilmek acil tıp hekimleri için çok önemlidir. Fibrinolitik tedavinin faydalı olduğu, morbidite ve mortalite riskini azaltırken kesin tedaviye köprü görevi görebileceği gösterilmiştir. Buna rağmen fibrinolitik tedavi az kullanılmaktadır ve sıklıkla optimum süreden daha geç verilmektedir. Fibrinolitiklerin amacı, ciddi ve potansiyel olarak yaşamı tehdit eden hasara yol açabilecek kan pıhtılarını çözmektir. Tedavinin yararı, kan akışının erken geri kazanılmasıyla doku beslenmesinin en üst düzeye çıkarılması ve böylece hem erken hem de uzun süreli sağ kalımı arttırması ile ilgilidir [1].

Fibrin, pıhtı oluşumunda en önemli mekanizmalardan biridir. Oluşan fibrin yapısı içerisinde bulunan plazminojen, trombolitik (fibrinolitik) ilaçlar tarafından plazmine dönüştürülür.Plazmin de fibrinağını parçalayarak damar içerisinde tekrar akım oluşmasını sağlar. Fibrinolitik ajanlardan, alteplaz (rekombinant doku plazminojen aktivatörü; rt-PA) en sık kullanılan fibrine özgü ilaçtır ve ülkemizde 2006 yılında onay almıştır. Diğer fibrine özgü ilaçlar ise reteplaz ve tenekteplazdır [2, 3].

Trombolitik tedavi, mekanik trombektomi gibi tedavi seçenekleri olmadığında, iskemik inmede tek tedavi seçeneği olabilmektedir. Buna rağmen tüm iskemik inme hastalarının \%20'si bu tedaviyi alması beklenirken sadece \%1 ila \%7'si bu tedaviyi alabilmektedir [4]. Bu oran ülkemizde net değildir fakat üçüncü basamak hastanelerde bu oranın devlet hastanelerine göre daha yüksek olduğu tahmin edilmektedir [5]. AMl'de ise kapı-balon süresinin 120 dakikaya kadar uzatılması ve artık birçok merkezde anjiografi yapılabilmesi nedeniyle trombolitik kullanımı oldukça azalmıştır ve daha sıklıkla üst merkeze sevk eden kurumlarda uygulanmaktadır [6,7]. Yine de AMI ile hastaneye yatırılan hastaların ancak \%50'sinin fibrinolitik tedavi için uygun olduğu belirtilmektedir [8]. Yine PTE tanısı alan hastaların yaklaşık \%10'unun trombolitik tedaviye intiyaç duyduğu belirtilmektedir [9].
Trombolitik kullanımı ile ilgili ulusal veriler ülkemizde neredeyse tamamen üniversite ve eğitim-araştırma hastanelerinden bildirilmektedir ve ikinci basamakta trombolitik kullanımı ile yeterli veri yoktur. Yayınlanan yazılar ise hastalığa spesifik tedavilerden ve olgu sunumlarında oluşmaktadır. Biz bu yazımızda, hastanemizde ilk kullanıma başladığı tarihten itibaren kullanılan tüm trombolitik tedavileri ve kullanıldıkları durumları belirlemek istedik. Ayrıca komplikasyon durumları ve hastaların 3 aylık mortalite durumlarını da kayıt altına almayı amaçladık.

\section{Gereç ve yöntem}

Çalışma, Ekim 2016-Temmuz 2018 yılları arasında Nevşehir Devlet Hastanesi acil servisinde retrospektif olarak yapıldı. Bu dönemden önce ise kayıtlarda herhangi bir trombolitik tedavi girişi bulunamadı. Acil servis, Nevşehir ili içerisindeki en büyük ve en çok hasta kabulü yapan ikinci basamak bir klinik niteliğinde olup, çalışma periyodu boyunca 311,349 erişkin ( $\geq 18$ yaş) hasta başvurusunu karşıladı (Ekim-Aralık 2016 döneminde 36,327; Ocak-Aralık 2017 döneminde 172,772; OcakTemmuz 2018 döneminde 102,250 başvuru). Hasta verileri hem trombolitik kayıt defterinden hem de hastane elektronik kayıt sisteminden elde edildi. Kullanılacak veriler, yaş, cinsiyet, başvuru tarih ve saati, özgeçmiş, tanı, kullanılan etken madde, komplikasyon durumu ve 3 aylık mortalite olarak belirlendi. Dışlama kriterleri, eksik ve kayıp veri olarak belirlendi.

Hastanemizde mevcutta bulunan trombolitik ilaçlar Alteplaz (Actilyse $®$ ) ve Tenekteplaz (Metalyse $®$ ), acil serviste de bulunmakta ve uygun hastalarda kullanılmaktadır. Klinik kullanım acil tıp uzmanı kararı ile veya ilgili branşın önerisi (göğüs hastalıkları, kardiyoloji, nöroloji) ile olmaktadır. Çalışma için etik kurul onamı Nevşehir Hacı Bektaş Veli Üniversitesi'nden 10.09.2018 tarihinde 2018.10.120 karar numarası ile alınmıştır.

\section{Veri Analizi}

İstatistiksel analiz IBM SPSS Statistics for Windows, Versiyon 21 (Armonk, NY: IBM Corp.) ve MedCalc $₫$ Versiyon 15,8 (MedCalc Software bvba, Ostend, Belgium) kullanılarak gerçekleştirildi. Sürekli veriler ortanca ve çeyrek aralıklar (IQR) olarak belirtildi. Kategorik veriler frekans ve yüzdeler olarak belirtildi. İki grup 
arasındaki normallik analizi Shapiro-Wilk analizi ile yapıldı. Sürekli veriler içeren ikili gruplar arasındaki fark Mann-Whitney testi ile bakıldı. Kategorik veriler Pearson's $x 2$ veya Fisher's exact testi ile karşılaştırıldı. Kritik a değeri, 05 olduğunda anlamlı kabul edildi.

\section{Bulgular}

Çalışma periyodu boyunca 57 hastaya trombolitik tedavi verildi. Hastaların ortanca yaşı 68 (IQR 54-79) ve erkek cinsiyet oranı $\% 70,2$ idi. Olguların \%17,5'ine $(n=10) 2016$ döneminde içerisinde, \%43,9'una ( $n=25) 2017$ ve \%38,6'sına ( $n=22) 2018$ döneminde tedavi uygulandı. Tüm çalışma boyunca trombolitik tedavi kullanım sıklığı 1,8/10.000 başvuruydu; 2016 döneminde 2,8/10.000, 2017 döneminde $1,4 / 10.000$ ve 2018 döneminde 2,2/10.000 başvuru oranındaydı. Tüm hastaların \%56,1'i 08:00-16:00 saatleri arasında, \%40,4'ü 16:0024:00 saatleri arasında ve \%3,5'i 24:0008:00 saatleri arasında acil servise başvurdu. Hastaların komorbiditelerine bakıldığında hipertansiyon \%43,9 oranında, koroner arter hastalığı ve kalp yetmezliği \%26,3, diabetes mellitus \%19,3, kronik obstruktif akciğer hastalığı \%14, atriyal fibrilasyon \%12,3, kronik böbrek hastalığı \%5,3 ve serebrovasküler hastalık öyküsü \%3,5 oranında saptandı. Hiçbir hastada malignite öyküsü saptanmadı.

Trombolitik tedavi uygulanan tanılar içerisinde; SVO \%50,9 oranında saptandı, AMI \%29,8, arrest etiyolojisi (kardiyopulmoner resüsitasyon [KPR] sırasında verilen) \%10,5 ve PTE \%8,8 oranındaydı (Tablo1). Arrest etiyolojisi tanısı, yüksek klinik şüphe üzerine acil hekiminin KPR sırasında kendi kararı veya uygun kliniğin önerisi ile trombolitik tedavi uyguladığı durumlardan oluşmaktaydı. Tedaviler arasında alteplaz $\% 75,4$ oranında ve tenekteplaz $\% 24,6$ oranında uygulandığı görüldü. Hastaların $\% 82,5$ 'inde $(n=47)$ tedavi sonrası herhangi bir komplikasyon saptanmamışken, \%3,5'inde $(n=2)$ kranial kanama, \%1,8'inde $(n=1)$ diş eti kanaması gelişti. Hastaların \%12,3'ü tedavi sürecinde arrest gelişip kaybedildiği için komplikasyon takibi yapılamadı. Tedavi uygulanan tüm hastaların 3 aylık mortalite oranı $\% 57,9$ idi.
Alteplaz uygulanan hastaların tanıları arasında ( $n=43)$; SVO \%67,4 oranında, AMI $\% 9,3$, PTE $\% 9,3$ vearrestetiyolojisi\%14 oranında saptandı (Tablo 1). Hastaların \%76,7'sinde tedavi ilişkili komplikasyon saptanmamışken, $\% 4,7$ oranında kranial kanama, $\% 2,3$ oranında diş eti kanaması geliştiği görüldü. Hastaların $\% 16,3$ 'ünde komplikasyon takibi yapılamadı. Hastaların 3 aylık mortalite oranı \%53,5 olarak izlendi. Mortalite gelişen bu hastaların dörtte birinde tedavi KPR sırasında verildi ve tanı netleştirilemedi. Mortalite izlenmeyen hastaların hiçbirinde ayrıca komplikasyon izlenmedi (Tablo 2).

Tenekteplaz uygulanan hastalarda ise $(n=14) ;$ AMI \%92,9 $(n=13)$ oranında izlenirken PTE \%7,1 ( $n=1)$ oranındaydı (Tablo 1). Tedavi ilişkili komplikasyon hiçbir hastada izlenmedi. Hastaların 24 saatlik mortalite oranı \%50 iken, 3 aylık mortalite oranı $\% 71,4$ olarak saptandı.

\section{Tartışma}

İskemik inme, akut miyokard enfarktüsü ve pulmoner embolizm, acil olarak tedavi edilmediğinde ciddi organ yetmezliği ve ölüme neden olabilecek durumlardır. Bunun sebebi ise sıklıkla akut tromboembolinin neden olduğu organlardakiyetersizkanakımıveoksijenizasyon eksikliğidir. Trombolitik uygulaması, bu blokajı geri çevirerek doku hasarını sınırlar ve hastanın kliniğine fayda sağlar [4]. Trombolitik tedavi, mekanik trombektomi gibi tedavi seçenekleri olmadığında, iskemik inmede tek tedavi seçeneği olabilmektedir. Buna rağmen tüm iskemik inme hastalarının \%20'si bu tedaviyi alması beklenirken sadece $\% 1$ ila $\% 7$ 'si bu tedaviyi alabilmektedir [5]. Bu oran ülkemizde net değildir fakat üçüncü basamak hastanelerde bu oranın devlet hastanelerine göre daha yüksek olduğu tahmin edilmektedir [6]. AMl'de ise kapı-balon süresinin 120 dakikaya kadar uzatılması ve artık birçok merkezde anjiografi yapılabilmesi nedeniyle trombolitik kullanımı oldukça azalmıştır ve daha sıklıkla üst merkeze sevk eden kurumlarda uygulanmaktadır [7, 8]. Yine de AMI ile hastaneye yatırılan hastaların ancak \%50'sinin fibrinolitik tedavi için uygun olduğu belirtilmektedir [9]. Yine PTE tanısı alan hastaların yaklaşık \%10'unun trombolitik tedaviye intiyaç duyduğu belirtilmektedir [10]. 
Tablo 1. Trombolitik tedavi uygulanan hastaların demografik özellikleri.

\begin{tabular}{clll}
\hline & $\begin{array}{l}\text { Total } \\
\mathrm{n}=57\end{array}$ & $\begin{array}{l}\text { Alteplaz } \\
\mathrm{n}=43\end{array}$ & $\begin{array}{l}\text { Tenekteplaz } \\
\mathrm{n}=14\end{array}$ \\
\hline Tanılar, $\mathrm{n}(\%)$ & & \\
SVO & $29(\% 50,9)$ & $29(\% 67,4)$ & $0(0)$ \\
AMI & $17(\% 29,8)$ & $4(\% 9,3)$ & $13(\% 92,9)$ \\
PTE & $5(\% 8,8)$ & $4(\% 9,3)$ & $1(\% 7,1)$ \\
Arrest etiyolojisi & $6(\% 10,5)$ & $6(\% 14)$ & $0(0)$ \\
Komplikasyon, n (\%) & & $3(\% 7)$ & $0(0)$ \\
Var & $3(\% 5,2)$ & $33(\% 76,7)$ & $14(\% 100)$ \\
Yok & $47(\% 82,5)$ & $7(\% 16,3)$ & $0(0)$ \\
Bilinmiyor & $7(\% 12,3)$ & & $10(\% 71,4)$ \\
3 aylık mortalite, $\mathrm{n}(\%)$ & & $23(\% 53,5)$ & \\
Var & $33(\% 57,9)$ & & \\
\hline
\end{tabular}

AMI, akut miyokard enfarktüsü; SVO, akut iskemik inme; PTE, pulmoner tromboemboli

Tablo 2. Alteplaz uygulanan hastalarda 90 günlük mortalite sonuçlarının analizi.

\begin{tabular}{clll}
\hline & $\begin{array}{lll}90 \text { günlük mortalite }(+) \\
\mathrm{n}=23\end{array}$ & $\begin{array}{l}90 \text { günlük mortalite }(-) \\
\mathrm{n}=20\end{array}$ & $p$ \\
& $70(54-79)$ & $72(60-78)$ & 0,874 \\
Yaş medyan (IQR) & $13(\% 56,5)$ & $15(\% 75)$ & 0,205 \\
Erkek cinsiyet, $\mathrm{n}(\%)$ & & & 0,023 \\
Tanı, n (\%) & $11(\% 47,8)$ & $18(\% 90)$ & \\
SVO & $3(\% 13)$ & $1(\% 5)$ & \\
PTE & $3(\% 13)$ & $0(\% 0)$ & 0,003 \\
AMI & $6(\% 26,1)$ & & \\
Arrest etiyolojisi & & $20(\% 100)$ & \\
Komplikasyon, $\mathrm{n}(\%)$ & $13(\% 56,5)$ & $0(\% 0)$ & \\
Yok & $3(\% 13)$ & $0(\% 0)$ & \\
Var & $7(\% 30,4)$ & & \\
Bilinmiyor & & & \\
\hline
\end{tabular}

AMI, akut miyokard enfarktüsü; SVO, akut iskemik inme; PTE, pulmoner tromboemboli

Çalışmamızda trombolitik tedavi uygulama oranı 1,8/10.000 acil başvurusu olarak görüldü. Bu oran 2016 döneminde 2,8/10.000, 2017 döneminde 1,4/10.000 ve 2018 döneminde 2,2/10.000 oranındaydı. Yıllara göre bu oranın değişiminin, hastanemizdeki sürekli değişen branş hekimlerinin tutumu, yoğun bakım ünitelerinin sıklıkla dolu olması ve bu hastaların başka merkeze sevk olması nedeniyle tedavinin farklı sıklıklarda kullanılmasıyla ilgili olabilir. Konu ile ilgili literatürde ise yeterli veri bulunamamıştır.

Trombolitik tedavi uygulanan tanılar içerisinde en sık SVO $(\% 50,9)$ tanısı olduğu görüldü. Diğer tanılar AMI $(\% 29,8)$, arrest etiyolojisi (KPR sırasında) $(\% 10,5)$ ve PTE' idi $(\% 8,8)$. Ülkemizde en sık ölüm sebeplerinden biri iskemik kalp hastalıkları sonrasında ise stroke hastaları gelmektedir. Fakat akut tedavi sürecinde trombolitik tedavi iskemik inmede neredeyse birçok merkezde tek tedavi seçeneği olarak karşımıza çıkmaktadır. AMl'de ise anjiografi uygun koşullarda ilk tedavi seçeneğidir. Hastenemizde de Temmuz 2016 tarihinden itibaren anjiografi işlemi yapılmaktadır. Bu sebeplerle çalışmamızda SVO en çok trombolitik tedavi uygulanan hastalık grubunu oluşturmaktadır. 
Alteplaz, hastanemizde aktif olarak kullanılan iki farklı trombolitik ajandan en sık kullanılanıydı. Bunun sebebi olarak ise daha fazla endikasyonu olmasına bağlandı [11]. Bu tanıların arasında SVO tanı oranının \%67'lere kadar çıktığı görüldü. AMI ve PTE her ikisinin oranı yaklaşık \%10 civarındaydı. Yüksek klinik şüphe üzerine (AMI veya PTE) KPR sırasında alteplaz uygulanan hastaların oranı yaklaşık \%15 idi. Böttiger ve ark. yaptığı ileriye dönük gözlemsel bir çalışmada kardiyak nedenli arrest olgularında alteplaz ve heparin uygulamasının güvenli ve hasta sonuçlarını düzeltebileceği sonucuna varılmış [12]. Fakat güncel çalışma sonuçları hala tartışmalıdır [13, 14]. Bizim çalışmamızda arrest etiyolojisi tanılı hastalar kaybedildiği ve tanıları netleşmediği için bu tanı grubunu oluşturmaktadır. Diğer hasta gruplarındaki KPR uygulaması çalışma amacı farklı olduğu için değerlendirilmemiştir.

Stroke hastalarında, rt-PA (alteplaz) uygulaması sonrası semptomatik intrakranial hemoroji sıklığı \%6 civarındadır. PTE hastalarında ise trombolitik sonrası hemorojik komplikasyon oranı \%9 civarındadır [15]. Bizim çalışmamızda kanama komplikasyonu alteplaz uygulaması sonrası \%7 olarak karşımıza çıktı. Yine de hastaların yaklaşık \%15'inde exitus geliştiği için komplikasyon takibi yapılamadı.

Tenekteplaz, alteplazdan daha uzun yarı ömürlü ve daha fazla fibrin spesifik üçüncü jenerasyon bir trombolitik ajandır. Tek doz uygulaması nedeniyle AMI'de daha fazla tercih sebebidir. İntrakrinal hemoroji riski alteplaz ile benzer fakat diğer kanama komplikasyonları daha azdır[16, 17]. Çalışmamızda hastanemizde anjio ünitesi olması nedeniyle tenekteplaz kullanım oranı oldukça düşük saptanmıştır. Kullanıldığı durumlardan birincisi; anjio ünitesi ilk açıldığı dönemde gece saatlerinde anjio yapılamamasıydı ve bu hastalar trombolitik tedavi intiyacı duyabiliyordu. Diğer bir durum ise eğer hasta anjio ünitesine çıkamayacak kadar unstabil durumda ise bu tedavi seçeneğine geçilmesiydi. Bu hastaların büyük bir kısmını da göğüs ağrısı ile acil servise başvurduğu anda ventriküler fibrilasyon veya kısa süreli arrest gelişen hastalar oluşturmaktadır. Bu nedenle tenekteplaz uygulanan hastaların yarısında 24 saat içerisinde mortalite gelişmiştir. Çalışmamızda bir PTE olgusuna tenekteplaz uygulandığı görülmüştür. Literatürde PTE vakalarında tenekteplaz uygulamasına dair birçok olgu ve çalışma rapor edilmiştir [18, 19]. Fakat halen konu tartışmalıdır.

Çalışmanın en büyük kısıtılığı, verilerin geriye yönelik olarak hastane kayıt sisteminin alınmasıydı. Ayrıca hastalara girilen tanıların veya konsültasyon notlarının eksik olduğu görüldü. İkinci basamak acillerde hasta yükünün çok fazla olması bu tür nedenlere sebebiyet verebilmektedir.

Sonuç olarak, ikinci basamak acil servislerde trombolitik tedavi uygulaması hakkında ulusal ölçekte yayınlanmış yeterli veri seti yoktur. Bu çalışma ile yaklaşık iki çalışma yılı sürecinde 57 hastaya bu tedavinin verildiği saptandı. Bu hastaların yarısı, il sınırlarımız içerisinde trombolitik ajanlar ile tek tedavi seçeneği olan SVO tanılı hastalardı. En sık kullanılan ajan ise, endikasyonu fazla olması nedeniyle, alteplazdı. Kılavuzlara uygun tedavi verilebilmesi açısından ve kritik hastalarda ülke genelinde stardardizasyon oluşturulması açısından ikinci basamak hastanelerde de bu tedavilerin yapılabilmesi ve hatta hekimlerin cesaretlendirilmesi uygun olacaktır.

Çıkar İlişkisi: Yazarlar çıkar ilişkisi olmadığını beyan eder.

\section{Kaynaklar}

1. Rivera-Bou WL, Chersich A. The role of fibrinolytic therapy in the emergency department. Bol Asoc Med P R 2016;108:61-64.

2. Hasanoğlu C. Trombolitik tedavi: kime, ne zaman, nasıl. Güncel Göğüs Hastalıkları Serisi 2015; 3:34-44. https://dx.doi.org/10.5152/gghs.2015.035

3. Kunt R. Treatment with intravenous thrombolysis in acute ischemic stroke through the perspective of a state hospital. Türk Beyin Damar Hast Derg 2016;22:91-99. https://dx.doi.org/10.5505/tbdhd.2016.47550

4. Johnson M, Bakas T. A review of barriers to thrombolytic therapy: implications for nursing care in the emergency department. J Neurosci Nurs 2010;42:88-94.

5. Johnson M, Bakas T. A review of barriers to thrombolytic therapy: implications for nursing care in the emergency department. J Neurosci Nurs 2010;42:88-94. https:// dx.doi.org/10.1097/JNN.0b013e3181ce5a48

6. Topçuoğlu MA, Arsava EM, Özdemir AÖ, Gürkaş E, Necioğlu Örken D, Öztürk Ş. Intravenous thrombolytic therapy in acute stroke: Problems and solutions. Turk J Neurol 2017;23:162-175. https://dx.doi.org/10.4274/ tnd.71084 
7. Ibanez B, James S, Agewall S, et al. 2017 ESC Guidelines for the management of acute myocardial infarction in patients presenting with ST-segment elevationThe Task Force for the management of acute myocardial infarction in patients presenting with ST-segment elevation of the European Society of Cardiology (ESC). Eur Heart J 2018;39:119-177. https://dx.doi.org/10.1093/eurheartj/ ehx393

8. Karaarslan S, Alihanoglu YI, Yildiz BS, et al. Appropriateness of the current guidelines on reperfusion treatment for patients applying to our hospital with STsegment elevation acute myocardial infarction. Turk Kardiyol Dern Ars 2012;40:493-498. https://dx.doi. org/10.5543/tkda.2012.68047.

9. Beton O, Zorlu A. Yoğun bakımda fibrinolitik tedavi. Turkiye Klinikleri Cardiology-Special Topics 2016;9:4250 .

10. Erkan L, Fındık S, Öztürk A, Akan H, Başoğlu T, Doru F. Masif pulmoner tromboembolide trombolitik tedavi. Solunum Hastalıkları 2002;13:163-171.

11. Thrombolytic Therapy. Available at: https://emedicine. medscape.com/article/811234-overview. Accessed December 8, 2018.

12. Bottiger BW, Bode C, Kern S, et al. Efficacy and safety of thrombolytic therapy after initially unsuccessful cardiopulmonary resuscitation: a prospective clinical trial. Lancet 2001;357:1583-1585. https://dx.doi. org/10.1016/S0140-6736(00)04726-7

13. Böttiger BW, Arntz H-R, Chamberlain DA, et al. Thrombolysis during resuscitation for out-of-hospital cardiac arrest. N Engl J Med 2008;359:2651-2662. https://dx.doi.org/10.1186/cc8906

14. Spohr F, Arntz HR, Bluhmki E, et al. International multicentre trial protocol to assess the efficacy and safety of tenecteplase during cardiopulmonary resuscitation in patients with out-of-hospital cardiac arrest: the Thrombolysis in Cardiac Arrest (TROICA) Study. Eur J Clin Inves 2005;35:315-323. https://dx.doi. org/10.1111/j.1365-2362.2005.01491.x

15. Abraham P, Arroyo DA, Giraud R, Bounameaux $H$, Bendjelid K. Understanding haemorrhagic risk following thrombolytic therapy in patients with intermediate-risk and high-risk pulmonary embolism: a hypothesis paper Open Heart 2018;5:e000735. https://dx.doi.org/10.1136/ openhrt-2017-000735

16. Davydov L, Cheng JW. Tenecteplase: a review. Clin Ther 2001;23:982-997. discussion 1. https://dx.doi. org/10.1016/S0149-2918(01)80086-2

17. Melandri G, Vagnarelli F, Calabrese D, Semprini F, Nanni S, Branzi A. Review of tenecteplase (TNKase) in the treatment of acute myocardial infarction. Vasc Health Risk Manag 2009;5:249-256.
18. Kline JA, Nordenholz KE, Courtney DM, et al. Treatment of submassive pulmonary embolism with tenecteplase or placebo: cardiopulmonary outcomes at 3 months: multicenter double-blind, placebo-controlled randomized trial. J Thromb Haemost 2014;12:459-468. https://dx.doi.org/10.1111/jth.12521

19. Kline JA, Hernandez-Nino J, Jones AE. Tenecteplase to treat pulmonary embolism in the emergency department. J Thromb Thrombolysis 2007;23:101-105. https://dx.doi. org/10.1007/s11239-006-9018-3

Bu çalışmanın etik kurul izni Nevşehir Hacı Bektaş Veli Üniversitesi'nden 10.09.2018 tarihinde 2018.10.120 karar numarası ile alınmıştır. 